Published in final edited form as:

Gastroenterology. 2019 January ; 156(2): 477-491.e1. doi:10.1053/j.gastro.2018.08.065.

\title{
Epidemiology and Management of Hepatocellular Carcinoma
}

\author{
Laura Kulik $^{1}$ and Hashem B. El-Serag ${ }^{2}$ \\ ${ }^{1}$ Division of Gastroenterology and Hepatology, Department of Medicine, Northwestern University, \\ Chicago, Chicago, Illinois, USA. \\ ${ }^{2}$ Section of Gastroenterology and Hepatology, Department of Medicine, Baylor College of \\ Medicine and Michael E. DeBakey Veterans Affairs Medical Center, Houston, Texas
}

\begin{abstract}
The major risk factors for hepatocellular carcinoma (HCC) in a contemporary clinical practice is becoming increasingly related to post sustained virological response hepatitis $\mathrm{C}$, suppressed hepatitis B virus on treatment, alcoholic and non-alcoholic fatty liver disease. We review the emerging data on the risk and determinants of $\mathrm{HCC}$ in these conditions, and the implications to HCC surveillance. However, from a public health perspective, active hepatitis $\mathrm{C}$ and $\mathrm{B}$ continue to drive most of the global burden of HCC. In United States, the age adjusted incidence rates of HCC in Hispanics have surpassed that of Asians. Prognosis in HCC is complex due to the competing risk imposed by underlying cirrhosis and presence of malignancy. In addition to tumor burden, liver function and performance status, additional parameters including tumor biopsy, serum markers and sub classification of current staging systems, taking into account patterns of tumor progression, may improve patient selection for therapy. Advancements in the treatment of HCC has included identification of patients that are most likely to derive a clinically significant benefit from the available therapeutic options. Additionally, the combination strategies of locoregional therapies and/or systemic therapy are being investigated.
\end{abstract}

\section{Keywords}

epidemiology; Hepatocellular carcinoma; hepatitis C

\section{Recent Epidemiological Trends in HCC}

The incidence and mortality of hepatocellular carcinoma (HCC) have been increasing in North America and several European regions and declining in traditionally high-risk regions, including Japan and parts of China. The main risk factors for $\mathrm{HCC}$ are chronic hepatitis $\mathrm{C}$

CORRESPONDING AUTHOR INFORMATION: Hashem B El-Serag, 7200 Cambridge Street, Houston, Texas, hasheme@bcm.edu, 7137986847.

Publisher's Disclaimer: This is a PDF file of an unedited manuscript that has been accepted for publication. As a service to our customers we are providing this early version of the manuscript. The manuscript will undergo copyediting, typesetting, and review of the resulting proof before it is published in its final citable form. Please note that during the production process errors may be discovered which could affect the content, and all legal disclaimers that apply to the journal pertain.

CONFLICTS OF INTEREST: Research grant funding for investigator initiated research from Gilead, Wako, and Merck to H ElSerag. Research grant funding for investigator initiated research from BMS to L Kulik. 
virus (HCV) or hepatitis B virus (HBV); heavy alcohol drinking; diabetes; and, possibly, nonalcoholic fatty liver disease (NAFLD). ${ }^{1} \mathrm{HCC}$ has been the fastest-rising cause of cancerrelated deaths in the United States. In an analysis including all 50 US states, HCC ageadjusted incidence rates increased from 4.4/100,000 in 2000 to 6.7/100,000 in 2012, increasing by $4.5 \%$ annually between 2000 and 2009 (Figure 1) ) $^{2}$ a similar increase in HCC related mortality has reported through 2016 (https://www.cdc.gov/cancer/liver/index.htm). There has been a recent slowing of the increase in incidence and mortality rates for HCC in the United States, with an annual increase of only $0.7 \%$ from 2010 through 2012. However, HCC incidence is disproportionately increasing in men ages 55 to 64 years-especially those born in the peak era of HCV infection and in certain ethnic/racial groups, including Hispanics, African Americans, and whites. Asian men had had the highest age-adjusted incidence rates attributed to chronic $\mathrm{HBV}$, especially among immigrants from $\mathrm{HBV}$-endemic areas. Subsequent generations of US-born Asians have much lower rates of HBV infection, and recent immigrants from HBV-endemic areas may be benefitting from reduced aflatoxin exposure and an increase in $\mathrm{HBV}$ vaccinations.

HCC age-adjusted incidence rates among Hispanics have surpassed those among Asians. The rates are higher in US-born Hispanics than in foreign-born Hispanics. The reasons are likely related to higher rates of HCV (particularly in Mexican Americans) ${ }^{3}$, alcoholic liver disease, NAFLD ${ }^{4,5}$, and metabolic syndrome, including diabetes, which increases the risk of developing HCC either independently or through potentiating the effect of viral hepatitis and alcoholic liver disease. Hispanics with chronic HCV or NAFLD have a higher risk of progression to cirrhosis and HCC, which may be partly a genetic (e.g., PNPLA3) predisposition.

The consistently high and increasing $\mathrm{HCC}$ incidence rates among individuals born in the peak-HCV cohort (1945-1965), irrespective of age or calendar year, are supportive of a potential birth-cohort effect related to $\mathrm{HCV}$ that has not decreased yet but that is anticipated to do so by 2020. The directly acting antivirals (DAA) may affect overall HCC incidence rates over the next 1-2 decades ${ }^{6}$; but the magnitude and timing of anticipated decreases in HCC incidence rates depend on the availability and penetration of HCV treatment, as well as increased detection, diagnosis, and linkage to care of individuals with chronic HCV infection.

\section{Changes in the Major HCC Risk Factors}

\section{HCV}

Patients with $\mathrm{HCV}$-induced cirrhosis are at particularly high risk for the development of HCC, with an annual incidence of HCC ranging from $0.5 \%$ to $10 \%$. Sustained virologic response (SVR) with DAA has emerged as the most dominant modifier of HCC in patients with HCV. Other than cirrhosis, the residual role of most traditional risk factors among those with active untreated or uncured $\mathrm{HCV}$ is unclear; these factors include older age, male sex, Hispanic ethnicity ${ }^{7}$, diabetes, obesity, smoking, HCV genotype $3^{8}$, heavy alcohol use, and $\mathrm{HIV}$ or HBV coinfection ${ }^{9}$. Although DAA is likely to change the epidemiology of HCV related $\mathrm{HCC}$ in those who are treated, most $\mathrm{HCV}$ infected populations remain untreated. ${ }^{10}$ 
Although few studies report a possibly unexpected high incidence of de novo and recurrent HCC after DAA treatment ${ }^{11}$, growing data consistently illustrate a considerable (50\%-80\%) and steady HCC risk reduction over time of de novo HCC among those achieving DAArelated SVR. DAA offer a chance of cure for patients with advanced cirrhosis, older patients, and those with alcohol use - all characteristics independently associated with risk of HCC in HCV. ${ }^{12-14}$ These patients were not treated or had poor response to interferon based treatment. Despite these historical differences, in a systematic review of 26 studies on de novo HCC occurrence (interferon =17, DAA=9), there was no evidence for differential HCC occurrence or recurrence risk following SVR from DAA and IFN-based therapy. ${ }^{15}$

The implications of SVR-related change in HCC risk on HCC surveillance are evolving. Kanwal et al. found that SVR achieved in patients with DAAs was associated with a $76 \%$ reduction in risk of HCC compared with patients who did not achieve SVR. ${ }^{16}$ The HCCpreventive effect of SVR was evident early on and increased over time. However, despite the relative reduction in risk of $\mathrm{HCC}$, the absolute risk of $\mathrm{HCC}$ persisted in patients with DAAinduced SVR. HCC developed in 183 patients during approximately 20,415 patient years' follow-ups, at an annual incidence of $0.90 \%$. Risk of HCC was the highest among those with cirrhosis, ranging from $1.0 \%$ to $2.2 \%$ per year, based on other demographic and clinical characteristics (Figure 2). These estimates reached or exceeded the cut-offs ( $0.8 \%-1.5 \%$ per year) beyond which HCC surveillance may become cost effective. ${ }^{17,} 18$ In contrast, the risk of HCC was low in almost all patients without cirrhosis, with the exception of patients with a high baseline FIB-4, suggesting presence of advanced fibrosis. Based on these data, HCC surveillance is likely to continue to be needed for all patients with cirrhosis or advanced fibrosis at the time of SVR. The extent of reduction of HCV related HCC is also dependent on screening and detection of the HCV infected cohorts, the dissemination of DAA treatments.

CHB is the leading etiology of HCC worldwide. The indications for antiviral therapy using nucleos(t)ide analogues (NAs) has been expanded in the past 1-2 decades to cover considerably more CHB patient groups. HBV can cause HCC in the absence of cirrhosis, although most cases of HBV-related HCC (70\%-90\%) occur in patients with cirrhosis. ${ }^{19}$ Risk factors for HCC in CHB include demographic (male sex, older age, Asian or African ancestry, family history of $\mathrm{HCC}$ ), viral (higher levels of HBV replication; HBV genotype; longer duration of infection; coinfection with HCV, HIV, or HDV), clinical (cirrhosis), and environmental (exposure to aflatoxin, heavy intake of alcohol or tobacco) factors.

However, like HCV treatment, NA viral suppression has emerged as the dominant modifier of HCC risk among patients with chronic hepatitis B (CHB). NA has been associated with risk reduction, but not elimination, of $\mathrm{HCC}$ in patients with $\mathrm{CHB} \cdot{ }^{20-22}$ Several scoring systems, such as CU-HCC, GAG-HCC, and REACH-B, were set up to predict the risk of HCC. ${ }^{23-25}$ Although these systems were externally validated and can attain high negative predictive values (above 95\%) for HCC development over a 3- to 10-year period in untreated patients, they may not adequately predict HCC in patients on NAs. ${ }^{26,}{ }^{27}$ Studies have shown that age, cirrhosis, male sex, platelet count, liver stiffness, and diabetes are risk factors of 
HCC in patients with CHB receiving NAs, ${ }^{28-30}$ while pretreatment viral load, HBeAg status, HBsAg quantity, or aminotransferase level is not predictive for treated patients. ${ }^{31-33}$ The Cirrhosis, Age, Male sex, Diabetes (CAMD) score was developed to predict HCC risk during the first few years of NA treatment, using data from patients continuously receiving entecavir or tenofovir for CHB in the national healthcare database in Taiwan ${ }^{34}$, and externally validated using the population-wide data extracted from the state-run healthcare database in Hong Kong (Figure 3) ${ }^{34}$ This score appeared to be similarly accurate as the well-established PAGE-B score that was validated in Caucasian and Asian populations. ${ }^{35}$ Although HCC incidence seems to decrease with cumulative NA treatment, it is unclear whether prolonged therapy can eventually eliminate the risk. Papatheodoridis et al. reported that a substantial risk of HCC remains after the first 5 years of entecavir or tenofovir treatment in patients with cirrhosis or aged above 50 years. ${ }^{36}$ It is also unclear how the risk of HCC may change following NA cessation.

Most knowledge about the risk of HCC in HBV is based on studies conducted in Southeast Asia and sub-Saharan Africa, where HBV infection is endemic and acquired at birth or early childhood. ${ }^{37}$ However, a multicenter study from the United States reported an annual incidence of $0.42 \%$; although more than $50 \%$ of the cohort was Asian Pacific Islander in origin. ${ }^{38}$ In addition, a recent cohort of 8329 , mostly male, patients was identified in the national Veterans Health Administration (VHA) database with CHB infection from 2001 through 2013. The annual HCC incidence was highest in American Pacific Islanders (0.65\%), followed by whites $(0.57 \%)$ and African Americans $(0.40 \%)$. There was no difference in HCC risk between African Americans and whites. HCC risk increased with age: adjusted HRs were 1.97 (95\% CI, 0.99-3.87) for 40-49 years; 3.00 (95\% CI, 1.555.81) for 50-59 years; and 4.02 (95\% CI, 2.03-7.94) for > 60 years vs. < 40 years. Patients with cirrhosis had higher risk of HCC than patients without cirrhosis (adjusted HR= 3.69; 95\% CI, 2.82-4.83). ${ }^{39}$ Even among patients without cirrhosis, the annual incidence of HCC was more than $0.2 \%$ for all patients $>40$ years with high levels of alanine aminotransferase, regardless of race and independent of HBV therapy.

The American Association for the Study of Liver Disease (AASLD) guidelines recommend HCC surveillance among HBV patients, based on the HCC incidence-rate thresholds of $0.2 \%$ or greater per year among those without cirrhosis, and between $0.2 \%$ and $1.5 \%$ per year among patients with underlying cirrhosis. ${ }^{17}, 18$ The guidelines use family history of $\mathrm{HCC}$, age, and race as additional criteria for HCC risk stratification in CHB. HCC surveillance is recommended for all patients with cirrhosis; and, in the absence of cirrhosis, for Asian men older than age 40 and Asian women older than age 50. The guidelines also suggest that surveillance should start at a younger age for Africans and African Americans than other races/ethnicities, without an exact specification of the age cut-off year, based on previous studies in South Africa, published in 1977 and 1988, which reported that African blacks with HBV might develop HCC at an age $<40$ years ${ }^{40,41}$. A recent multi African country study confirms the younger age of HBV-related HCC in these countries. ${ }^{42}$

Although recent US-based studies confirmed the age effect observed in the studies conducted in East Asia, the risk of HCC increased with age, and the inflection point for markedly increased risk of HCC was among those older than 40 years, the VHA cohort data 
indicate an extremely low risk of HCC in all individuals younger than 40 years, including African American patients (annual incidence, 0.03\%). Furthermore, irrespective of age, the risk of $\mathrm{HCC}$ among African Americans with chronic HBV was not significantly different from the risk in whites. These data show that, in the United States, African Americans with chronic HBV may not need surveillance at an earlier age than patients of other racial groups. This recommendation may still be relevant to Africans in whom aflatoxin exposure plays an additional role.

\section{NAFLD}

NAFLD has become the leading cause of chronic liver disease in most regions of the world, including the United States ${ }^{43}$, with up to $30 \%$ prevalence in the general population. ${ }^{44} \mathrm{An}$ estimated 20-30\% of patients with NAFLD develop progressive liver disease with necroinflammation and fibrosis that can result in cirrhosis in 10-20\% of cases. ${ }^{45}$ The prevalence of NAFLD and risk of progression is higher among Hispanics than other racial and ethnic groups. ${ }^{46}$ NAFLD is the fastest-growing cause of HCC related transplant in the United States ${ }^{47}$, although the exact magnitude, timing and determinants of HCC in NAFLD cases are unclear. A systematic review of epidemiological studies (published through 2011) examining the NAFLDHCC link found mixed results, with HCC risk ranging from $0 \%$ to $38 \%$ over 5 to 10 years of follow-up ${ }^{48}$; subgroups with cirrhosis were at distinctly high HCC risk. Most published studies included small or modest-sized NAFLD cohorts and, thus, had few or no incident HCC cases. Furthermore, most studies evaluated patients in tertiary care settings. Thus, the generalizability of these findings to community-based clinical populations with NAFLD is unclear.

HCC occurring in the absence of cirrhosis is unusual and mainly occurs in up to $15 \%$ of HBV-related cases. Among new HCC cases without advanced fibrosis or cirrhosis in the United States, NAFLD constitutes the largest etiological proportion of cases. ${ }^{49}$ This entity poses a challenge to clinical practice paradigms based on HCC risk mediated through cirrhosis. A lower proportion of patients with NAFLD-related HCC receive HCC surveillance before their HCC diagnosis or HCC-specific treatment than of patients with HCV-related HCC. ${ }^{49}$ The available data on HCC risk support screening among patients with NAFLD related cirrhosis, but it may be cost effective for patients with advanced fibrosis especially those with multiple components of the metabolic syndrome and Hispanics.

Irrespective of NAFLD, diabetes and obesity increase HCC risk. Type 2 diabetes was associated with 2 to 3 -fold increase in the risk of $\mathrm{HCC}^{50}$, including in cohort studies that reduce the likelihood of reverse association. ${ }^{51}$ The use of metformin is associated with decreased risk, while the use of insulin or sulfonylureas may increase HCC risk. ${ }^{52}$ Longer duration of diabetes may be associated with an incremental increase in risk. ${ }^{53-55} \mathrm{~A}$ predictive model that was developed in patients with cirrhosis on the national liver transplantation waitlist database used diabetes in addition to age, race, etiology of cirrhosis, sex, and severity of liver dysfunction to predict the 1-year risk of HCC. ${ }^{56}$ Most-but not all-of studies are suggestive of a modest increase in the relative risk of HCC in obese persons. A systematic review of 10 cohort studies found a positive association between obesity, measured as body mass index, and risk of HCC in seven studies (relative risks ranging from 
1.4 to 4.1 ), no association in two, and an inverse association in one study. ${ }^{57}$ Moving beyond BMI and into more proximal features in the association between BMI and HCC, a cohort found that a high waist-to-hip ratio conferred a 3-fold higher HCC risk to subjects in the upper tertile of waist hip ratio than those in the lowest tertile. ${ }^{58}$

Population attributable fraction (PAF) is the proportion of cases with disease (i.e., HCC) that can be avoided by removing the underlying risk factor (i.e., NAFLD). PAF is calculated using the prevalence (how common) and risk estimate (how strong). HCV and HBV are uncommon but strong HCC risk factors in the general population; their PAFs are less than that of NAFLD, a highly prevalent but weak risk factor. ${ }^{59}$ Nevertheless, population-based studies demonstrate that HCV remains the leading cause of HCC in the United States. In a national study among liver-transplant recipients, NAFLD is the most rapidly growing cause between 2002 and 2016 of HCC among U.S. patients listed for liver transplantation; but HCV remained the leading HCC etiology. ${ }^{60}$ In the US VHA hospital system, the annual proportion of NAFLD-related HCC remained stable during 2005 to $2010(7.5 \%-12.0 \%)$, while that of HCV-related HCC increased from $61.0 \%$ to $74.9 \%{ }^{5}$. The explanations for the divergence between high PAF for NAFLD-related HCC and studies showing a relatively low proportion of NAFLD among newly diagnosed HCC is likely related to the fact that PAF does not consider temporal lag between risk-factor acquisition and HCC development; it may take several decades for cohorts affected with NAFLD to develop HCC in large numbers. ${ }^{61}$

\section{Diagnosis of HCC}

The goal of surveillance is to detect HCC at an early stage when curative options are feasible. The AASLD criteria for diagnosis of HCC in a patient with cirrhosis have been based on well-defined imaging characteristics (arterial enhancement with postarterial washout) without the need for a confirmatory biopsy. ${ }^{62}$ In 2011, the American College of Radiology introduced the Liver Imaging Reporting and Data System (LIRADS) to standardize the reporting of liver lesions. LI-RADS encompasses 5 categories, with LR5 representing a definitive imaging diagnosis of HCC. More rigorous criteria were required for lesions $1.0-1.9 \mathrm{~cm}$ compared to lesions $\geq 2 \mathrm{~cm}$. The most updated LI-RADS v2018 have amended the criteria for $1.0-1.9 \mathrm{~cm} \mathrm{LR}-5$ lesions to match ${ }^{63}$ those of the updated 2018 ASSLD criteria: both state that a $1.0-1.9 \mathrm{~cm}$ lesion may be categorized as LR- 5 if benign lesions and non-HCC malignancy have been excluded from consideration and there is a nonrim arterial phase hyperenhancement in combination with either washout or threshold growth, regardless of capsule appearance. The imaging feature of an enhancing capsule appearance is now required only in lesions $\geq 2 \mathrm{~cm}$ with neither washout appearance nor growth. (https://www.acr.org/Clinical-Resources/Reporting-and-Data-Systems/LI-RADS).

For transplant prioritization, however, OPTN still requires washout plus capsule appearance if 50\% growth within 6 months is not present in arterial enhancing lesions $1-1.9 \mathrm{~cm}$.. A recent study found that LIRADS did not outperform the AASLD criteria for HCC diagnosis in single lesions $23 \mathrm{~cm} .{ }^{64}$ Data are being collected to address unanswered questions and update LI-RADS every $3-5$ years. ${ }^{65}$ 
When contrast-enhanced imaging is not feasible or the findings are not characteristic of HCC, a targeted biopsy is warranted. Initial reports of complications such as needle track seeding varied from $3 \%$ to $9 \%$. A meta-analysis of 8 studies reported a $2.7 \%$ risk of needle track seeding, pathologically confirmed, with a median time of diagnosis of 17 months from diagnostic biopsy. ${ }^{66}$ This risk was $0 \%$ in a subsequent study, which employed a co-axial cutting needle technique ${ }^{67}$. Multiple biopsies may be required to minimize sampling error with a false-negative result and with a negative biopsy, close follow-up imaging is recommended in a suspicious lesion. ${ }^{68}$

\section{HCC Prognosis}

HCC treatment options depend on tumor burden, degree of liver dysfunction, and performance status. The Barcelona Clinic for Liver Cancer (BCLC) staging system, which pairs these parameters with a recommended therapy is the most widely used. ${ }^{70}$ The median overall survival associated with therapy based on the BCLC stage provides providers and patients with realistic expectations regarding anticipated average life expectancy. Overall survival is considerably shorter in patients with untreated HCC (Supplementary Table 1). 71,72

The Hong Kong Liver Cancer staging system also takes into account prognostic factors and pairs each stage with a recommended therapy. ${ }^{73}$ The HKLC system consists of 9 stages and recommends more aggressive therapy among subsets of patients compared to the BCLC including resection in multiple tumors and those with intrahepatic vascular invasion. This system will require prospective validation in Western patients to determine if the proposed therapies do indeed lead to improved OS.

\section{The Role of Tumor Biopsy in HCC}

A tumor biopsy is utilized in some centers as a selection tool for OLT to disqualify OLT in patients with poor prognostic features, however is not considered standard of care. The Extended Toronto Criteria for liver transplant has no limitation in tumor size or number, barring any systemic cancer-related symptoms (defined as weight loss exceeding $10 \mathrm{~kg}$ and performance status $>0$ ), extrahepatic spread and vascular invasion. However, if the tumor burden exceeds the Milan criteria, a biopsy is mandatory of the largest lesion to rule out poorly differentiated HCC, which excludes OLT. ${ }^{74}$ In a retrospective study, those exceeding the Milan criteria but meeting the Extended Toronto Criteria had a 5-year overall survival post OLT of $70 \%$.

In a prospective study using the Extended Toronto Criteria in 243 patients with HCC listed for OLT, $43 \%$ exceeded the Milan criteria and underwent tumor biopsy prior to listing to exclude poorly differentiated HCC; $18 \%$ dropped out due to tumor progression. ${ }^{75}$ The remaining 72 patients underwent OLT and had a 5 -year post OLT overall survival of $68 \%$. There was a non-significant increase in HCC recurrence post OLT among those who exceeded versus those meeting the Milan criteria (26\% vs. $16 \%, \mathrm{p}=0.09)$.

Tumor biopsy may also provide prognostic information on a molecular level. However, the utilization of gene signatures is limited by assessment to tumor tissue outside clinical studies and concern for heterogeneity within a tumor that could alter the predictive capability. 
Tumor biopsies would be expected to increase with development of targeted therapies against identified driver mutations. Furthermore, despite advancements in the molecular pathogenesis of HCC, systemic therapies with proven survival benefit have no known molecular signature to predict response. ${ }^{76}$ In a biomarker study of the STORM trial, gene signatures failed to predict recurrence or prevention of HCC recurrence associated with adjuvant sorafenib use. ${ }^{77}$ In HCV-induced HCC, examining tumor tissue identified genetic signatures enriched with immune cells in approximately $24 \%$ of cases, which were further subdivided based on the tumor microenviroment. An active immune response within the stroma was an independent predictor of overall survival in patients who underwent resection for HCC. ${ }^{78}$ This may offer insight into predicting response to immune check-point inhibitors.

\section{Liver Transplant}

OLT offers the best chance for oncologic cure. However, access to OLT is based on the Milan criteria, which are dependent upon tumor size and number (1 lesion $5 \leq \mathrm{cm}$ or 2-3 lesions with none exceeding $3 \mathrm{~cm}$ ). Predictors of HCC recurrence post OLT, beyond tumor size and number, have emerged, including microvascular invasion (limited availability preOLT), serum AFP and neutrophil-lymphocyte ratio (NLR).

Serum AFP has established its role as an important prognostic marker in HCC. AFP > 1000 $\mathrm{ng} / \mathrm{mL}$ has been reported in several studies to be an independent predictor of inferior post OLT outcomes ${ }^{79-81}$, with recurrence rates approaching 50\%. An AFP increase $>7.5 \mathrm{ng} / \mathrm{mL}$ per month using several AFP data points was significantly associated with microvascular invasion and $\mathrm{HCC}$ recurrence posttransplant. ${ }^{82}$ These data support the recent inclusion of an AFP threshold in the United Network for Organ Sharing eligibility criteria for an HCC MELD upgrade. If the AFP $>1000 \mathrm{ng} / \mathrm{ml}$ a HCC MELD upgrade is not automatic in T2 lesions. In order to qualify for a standard MELD upgrade, the AFP must declines to $<500$ $\mathrm{ng} / \mathrm{ml}$ after LRT and in those with an AFP $\geq 500 \mathrm{ng} / \mathrm{ml}$ anytime following LRT are referred to the review board as a special case. The AFP closest to OLT is the most informative value in predicting post OLT outcomes. A rising AFP is associated with increased post OLT mortality independent of tumor burden. ${ }^{83}$

Approximately $1 / 3$ of HCC tumors are non-AFP producers. It is unknown whether non-AFP tumors are biologically similar to those with an elevated AFP that declines with LRT. An analysis of patients with an AFP persistently $<10 \mathrm{ng} / \mathrm{mg}$ while awaiting OLT showed a significantly lower proportion of microvascular invasion and poorly differentiated tumor on explant, both risk factors for HCC recurrence. Overall and recurrence free survival were superior in the AFP $<10 \mathrm{ng} / \mathrm{mL}$ compared to AFP-producing tumors after stratifying for radiographic Milan status. Five-year overall survival was $71 \%$ in non-AFP producers within Milan criteria on imaging, and recurrence rate was only $6 \%$. These data suggest that persistently normal AFP tumors have a less aggressive biological behavior than AFPproducing tumors. However, this conclusion is tempered by the AFP $<10 \mathrm{ng} / \mathrm{mL}$ group's having received a greater number of LRTs prior to OLT.

Blood and tissue markers of chronic inflammation carry some prognostic value in various malignancies, including HCC. The blood NLR may predict HCC recurrence post OLT. In a 
meta-analysis of 13 studies (1936 LT) the pre-transplant NLR (cut off $2.3-6.0$ ) was associated with an inferior overall survival (HR 2.22; 95\% CI 1.34-3.68), recurrence free survival (HR 3.77; 95\% CI 2.01-7.06), explant characteristic including microvascular invasion (0R 2.39; 95\% CI 1.20-4.77) and lower likelihood of meeting the Milan criteria (OR $0.26 ; 95 \%$ CI $0.17-0.40) .{ }^{84}$ A subgroup analysis suggested a pre-LT NLR cut off of $\geq$ 4.0 has optimum prognostic performance. Further research is needed to verify whether age, LRT, HCV therapy and time elapsed from NLR measurement to OLT influence the prognostic capability of NLR.

Proponents of expanding the Milan criteria have been unsuccessful in devising and testing a widely accepted alternative. Combining various biological parameters into scoring systems that include radiographic response to LRT, tumor markers (AFP or DCP/PIVKA levels), NLR and waiting time has been proposed ${ }^{85-87}$; RFS post-OLT is significantly lower in those exceeding the determined cut offs in these scoring systems for both tumors within as well as exceeding the Milan Criteria (Table 1).

\section{Prognosis in Intermediate and Advanced HCC}

BCLC B represents a heterogeneous group of patients. Chemoembolization is the standard of care, based on several RCTs, which demonstrated improved overall survival compared to best supportive care. ${ }^{88,89}$ A subclassification consisting of 4 subgroups (B1-B4) has been proposed..$^{90}$ Those characterized as B1 (CP 5-7, normal performance status and up-to-7 tumor burden) had a median overall survival of 41 months. Similar overall survival (47.7 months) has been reported in highly selected patients treated with TACE and drug-eluding beads. ${ }^{91}$

\section{BCLC C}

Advanced HCC carries a poor prognosis; however, BCLC C stage is also quite heterogeneous. In a retrospective study of 835 patients with BCLC C HCC, differences in median overall survival were noted, based on the criteria that led to advanced HCC assignment. ${ }^{92}$ Median overall survival was significantly different, based on performance status (grade 1: 38.6 months, grade 2: 22.3 months), presence of extrahepatic spread (11.2 months) or macrovascular invasion (MVI) (peripheral portal vein thrombosis 11.2 months, main portal vein thrombosis 7.1 months). Receipt of therapy also varied based on these components of the BCLC C stage, with curative options highest among those with PS1. This suggests that PS 1 alone should not result in classification of advanced HCC

Patterns of HCC progression with sorafenib significantly impact postprogression survival. ${ }^{93}$ Three patterns of progression include increase in intrahepatic/extrahepatic tumor size, new intrahepatic lesion, and new extrahepatic lesion. Development of a new extrahepatic lesion and/or new vascular invasion is an independent predictor of PPS. ${ }^{94}$ 


\section{Therapeutic Advances \\ Very Early HCC}

Radiofrequency ablation (RFA) or resection is the main treatment option; and the choice depends on age; tumor location; comorbidities; and absence of clinically significant portal hypertension (CSPH), defined as hepatic venous pressure gradient $<10 \mathrm{mg} / \mathrm{Hg}$ and bilirubin $<1.0 \mathrm{md} / \mathrm{dL}$. There is no clear data-driven approach, with no RCTs in very early HCC comparing resection to ablation in candidates for either therapy. Response rates to ablation are excellent, with 5-year overall survival of up to $68 \% .{ }^{95}$ The BRIDGE Study reported a significantly lower overall survival associated with ablation in nonideal candidates for resection compared to resection..$^{96}$ Therefore, a common approach is to "wait and not ablate" until a lesion reaches $2 \mathrm{~cm}$; this has a $<10 \%$ chance of progression beyond the Milan criteria. ${ }^{97}$ and is endorsed by the ASSLD in patients with a T1 lesion listed for OLT. ${ }^{98}$ An alternative approach in CP A patients with early $\mathrm{HCC}$ is resection or ablation as first-line therapy, with OLT reserved only for tumor recurrence or hepatic decompensation. ${ }^{99}$ The third approach is surgical resection in otherwise suitable candidates for OLT to determine the presence of high-risk features (vascular invasion, satellite lesions, poorly differentiated tumor) and early transplantation prior to HCC recurrence. ${ }^{100}$ The recent AASLD guidelines recommend resection over RFA in compensated $\mathrm{T} 1$ and $\mathrm{T} 2$ disease. A subsequent Cochran review that included 4 RCTs in resectable T1/T2 HCC comparing resection to RFA found no significant difference in overall survival between the 2 approaches.

\section{Hepatic Resection}

Advancements in surgical technique, patient selection and perioperative care have significantly reduced surgical mortality to $1-3 \%$ at experienced centers. ${ }^{101}$ The BCLC recommends resection in CP A patients with a single lesion (no size limit) without (CSPH). In a study of over 8000 patients in a multiregional cohort that assessed surgical management of newly diagnosed HCC, only $10 \%$ were considered ideal candidates for resection. ${ }^{96}$ Even in patients with no CSPH and bilirubin $<1.0 \mathrm{mg} / \mathrm{dL}$, the future liver remnant may not be $\geq$ $40 \%$ to sustain adequate liver function postresection. In such cases, growth of the FLR may be induced via portal vein embolization. ${ }^{102}$ However, a concern is tumor growth while awaiting hypertrophy. Radioembolization has been used as a bridge to resection by treating the tumor and simultaneously inducing contateral hypertrophy, thereby increasing the FRL by $26-47 \%$ over 44 days- 9 months. ${ }^{103,104}$

Five-year recurrence rates approach $70 \%$ postresection, with $2 / 3$ of recurences occuring within 2 years related to intrahepatic spread. To date, no effective adjuvant therapy has been reported, including sorafenib. ${ }^{105}$ The potential for early HCC recurrence postresection associated with DAAs has been hypothesized to be related to a dampening of tumor immune surviellence with rapid virologic clearance. ${ }^{11}$ However, subsequent analysis has offered the alternative explantion of a selection bias related to the proximity of initiation of DAA therapy postresection. ${ }^{106}$

Resection in a subset of patients with preserved synthetic function and MVI of first-order (V1) or peripheral branches (V2) has been reported to achieve significantly improved overall 
survival compared to nonsurgical therapy in a Japanese cohort. ${ }^{107}$ Further research is required before advocating this approach.

\section{Bridging to Transplant}

Patients awaiting OLT for HCC are at risk of tumor progression beyond the Milan criteria (T2) and, hence, waitlist drop out. Therefore, LRT is often employed to delay tumor growth and maintain priority for transplant. A meta-analysis of 2 studies reported that receipt of any form of LRT was associated with a non-significant decrease in drop out related to HCC progression and drop out from all causes compared to no LRT prior to OLT. ${ }^{108}$ Furthermore, there was no significant difference in overall survival and recurrence post-LT found to be associated with LRT. There was a high risk of selection bias and no RCTs. The updated AASLD guidelines recommend LRT in patients with T2 HCC listed for OLT but do not endorse a specific therapy. ${ }^{98}$ A subsequent single-center study conducted over 6 years ${ }^{109}$ in 45 BCLC A/B patients randomized to TACE or Y90, with repeat therapy based on radiographic response. Time to tumor progression (TTP) was significantly longer in Y90: 6.8 months for cTACE and not reached for $\mathrm{Y} 90$ (>26 months; HR $=0.122, \mathrm{P}=0.007$ ). Overall survival censored to LT was not significantly different between the 2 (TACE 17.7 vs. Y90 18.6; $\mathrm{P}=0.99$ ).

\section{Downstaging to Transplant}

LRT to induce tumor necrosis and downstage to the Milan criteria has increased access to OLT in select patients. Successful downstaging has been reported in $24-90 \%$ due to heterogeneity in radiographic assessment; downstaging protocols, including entry criteria and use of biological markers in addition to tumor size/number; and time-out period post response prior to listing. ${ }^{110} \mathrm{~A}$ meta-analysis reported a pooled success rate of $48 \%$, with HCC recurrence of $16 \%$ post-OLT. ${ }^{111}$ Multimodal therapy was associated with higher rates of downstaging. In this analysis, downstaging was a radiographic endpoint; therefore, all patients included may not have been considered OLT candidates. A prospective downstaging study in OLT candidates reported no significant difference in 5-year post OLT overall survival between those downstaged and T2 patients at listing: $90 \%$ vs. $88 \%$, respectively, with acceptable $\mathrm{HCC}$ recurrence of $7.5 \%$ among the downstaged cohort. ${ }^{12}$ A subsequent multicenter, retrospective study confirmed excellent posttransplant outcomes. ${ }^{113}$ AFP > 1000 prior to LRT and CP B/C predicted treatment failure. UNOS has recognized the role of downstaging, and it is now part of policy for allocation. Patients who meet eligibility for downstaging (i.e., 1 lesion $>5 \mathrm{~cm}$ and $\$ 8 \mathrm{~cm}$, or 2-3 lesions each $<5 \mathrm{~cm}$ and total diameter of all lesions $\$ 8 \mathrm{~cm}$, or 4-5 lesions each $<3 \mathrm{~cm}$ and total diameter of all lesions $\$ 8 \mathrm{~cm}$ ) and are successfully downstaged to the Milan criteria are eligible for the standard HCC MELD upgrade.

The most reported common downstaging modality is chemoembolization. External- beam radiation as a bridge to OLT in a single-center study showed no significant difference in drop-out rate, overall survival from listing, or OLT compared to RFA or TACE. ${ }^{114}$ Radiotherapy may be an alternative therapeutic option when TACE or RFA is not feasible. 


\section{Radioembolization}

Radioembolization has been used across the BCLC. ${ }^{115}$ Although no difference in overall survival has been demonstrated between radioembolization compared to chemoembolization in BCLC A/B, Y90 has been shown to be feasible and safe in patients with MVI. Improvement in overall survival, particularly among patients with PVT, may be feasible by using a personalized approach with glass microspheres. A tumor threshold dose of $>205 \mathrm{~Gy}$ has shown a significant improvement in overall survival and radiographic response rates compared to $<205$ Gy. ${ }^{116}$ The tumor radiation dose and ${ }^{99 m} \mathrm{Tc}$ macroaggregated albumin (MAA) quantification uptake into the tumor/PVT can stratify patients into good (PVT uptake on MMA + > $205 \mathrm{~Gy}$ ) versus poor candidates. ${ }^{117}$

A prognostic model can identify patients with PVT (excluding main PVT) anticipated to derive a significant benefit with Y90 versus those to avoid due to futility. ${ }^{118}$ Three variables consisting of bilirubin ( $\triangle .2 \mathrm{vs}$. $>1.2 \mathrm{md} / \mathrm{dL}$ ), extension of PVT (segmental. second order, first order), and tumor burden ( $\leq 50 \%$ vs. $>50 \%$ ) were used to construct prognostic categories. Patients with a favorable prognosis ( 0 points) had a median overall survival of 32.2 months. Median overall survival was significantly lower in those with intermediate prognosis (2-3 points) and dismal prognosis (>3 points), at 14.9 and 7.8 months, respectively.. ${ }^{119-121}$

\section{Combination Therapy in Early or Intermediate HCC}

TACE+RFA-TACE plus RFA is used to attempt to overcome the limited ablation in target lesions exceeding $3 \mathrm{~cm}$. RCTs comparing TACE + RFA versus RFA alone have been limited by insufficient power. ${ }^{122}$ In a meta-analysis of 8 RCTs, patients with lesions $>3 \mathrm{~cm}$ have shown higher overall survival associated with combination therapy, with no significant increase in major complications compared to TACE alone. No RCTs have compared the efficacy of TACE + RFA with TACE. A small non-RCT trial comparing DEB + RFA vs. DEB reported significantly longer 2-year overall survival and lower recurrence rates in the combination arm. ${ }^{123}$

\section{TACE + tyrosine-kinase inhibitors (TKIs)}

The intended synergy of combining sorafenib with TACE is to blunt the angiogenic surge associated with embolization-induced hypoxemia, thereby extending TTP and improving overall survival. Initial studies of this approach reported varied results. A meta-analysis of 6 trials concluded that the combination of sorafenib and TACE results in improved overall survival and TTP compared to TACE monotherapy. ${ }^{124}$ However, subsequent large RCTs comparing TACE/DEB + TKIs to TACE/DEB alone failed to show a clinical benefit with combination therapy. TKI timing of initiation related to TACE/DEB, dosage, duration and early terminations of trials may have affected the results. ${ }^{125}$ In the SPACE trial, one third of the patients in the combination arm received only 1 session of DEB due to conservative stopping rules.

A phase II trial in Japan of 156 patients, Transcatheter Arterial Chemoembolization Therapy in Combination With Sorafenib, reported a significantly longer progression free survival in patients who received TACE + sorafenib versus TACE alone, 25.2 vs. 13.5 months, 
respectively (HR $0.59,95 \%$ CI $0.41-0.87 ; \mathrm{p}=0.006) .{ }^{126}$ The study design may explain the positive results. In contrast to prior trials, new intrahepatic lesions did not constitute progression that led to discontinuation of assigned therapy. The median duration of sorafenib in this trial was longer (38.7 weeks), compared to prior studies (TACE 2, SPACE, PostTACE), ranging from $17.0-24.0$ weeks. Most (89\%) patients had no prior treatment with TACE. This, along with TACE administered on demand as opposed to scheduled, may have contributed to preservation of liver function to allow continuation of sorafenib. The coprimary endpoint of overall survival is not yet available.

\section{Therapy in Advanced HCC}

Sorafenib is the standard treatment in patients with advanced HCC, based on improved overall survival in RCTs compared to placebo. ${ }^{98,122,127,128}$ Predictive factors for sorafenib benefit in advanced HCC have been retrospectively identified,. ${ }^{129}$ Overall survival was significantly extended with sorafenib in those with HCV (HR 0.47 vs. 0.81), no extra hepatic spread (HR 0.55 vs. 0.84 ) and a low NLR (HR 0.59 vs. 0.81) compared to placebo. MVI, high AFP (> $200 \mathrm{ng} / \mathrm{mL}$ ) and high NLR were poor prognostic factors for overall survival in the entire cohort First and second line agents have subsequently been positive in phase 3 RCTs in unresectable HCC (Table 2)

\section{Radioembolization +/- Sorafenib}

The first large RCT, phase II, examining sorafenib versus Y90 (resin microspheres) plus sorafenib in inoperable, locally advanced HCC, SORAMIC (SORAfenib in combination with local MICrotherapy guided by gadolinium-EOB-DTPA-enhanced magnetic resonance imaging) showed no significant difference in primary endpoint, overall survival in the intended-to-treat analysis, 12.1 (sorafenib $+\mathrm{Y} 90, \mathrm{n}=216$ ) vs. 11.5 months (sorafenib, $\mathrm{n}=208$ ), $\mathrm{p}=0.93 .{ }^{135}$ Subgroup analyses of the patients treated per protocol identified improved overall survival in the Y $90+$ sorafenib arm in patients $<65$ years old, with nonalcoholic etiology of liver disease and without cirrhosis. Increased adverse events, $\geq$ grade 3 , were noted in the combination group (73\%) compared to sorafenib alone $(65 \%)$.

Two other RCTs failed to show superiority of Y90 over sorafenib in advanced HCC. ${ }^{136,137}$ In both trials, approximately 1/3 of patients in the Y 90 arm and 7-9\% in the sorafenib arm did not receive their planned therapy; and treatment-related adverse events were significantly lower in the Y90 group.

\section{TACE + External Beam Radiotherapy (RT)}

A meta-analysis of 25 Eastern trials ( $11 \mathrm{RCTs}, \mathrm{n}=2577$ patients) reported improved pooled overall survival (TACE + RT 22.7 mo. vs. TACE 13.5 mo.; p <0.001) but higher rates of gastric/duodenal ulcers and elevation in transaminases with TACE + RT compared to TACE alone. ${ }^{138}$ An RCT in 90 patients with HCC, CP A, with MVI without extrahepatic spread, $84 \% \mathrm{HBV}$ and no prior HCC treatment evaluated the safety and efficacy of TACE + RT vs. sorafenib alone (400 Gy twice daily, mean dose was 739/d). ${ }^{139}$ Most patients with PVT had unilateral disease (58.9\%),. TACE was performed every 6 weeks; and RT was initiated 3 weeks after the initial TACE, with a planned total dose of $45 \mathrm{~Gy}$ to the targeted area. The primary endpoint of 12-week PFS was significantly higher in the TACE-RT group than in 
sorafenib; $86.7 \%$ vs. $34.3 \%$, p < 0.001. Independent of MVI extent, 24-week PFS remained significantly higher in the TACE-RT group. Median TTP and overall survival were also significantly higher in the combination group (TTP: 31.0 vs. 11.7 weeks; overall survival: 55 vs. 43 weeks, respectively). Treatment crossover rate at 24 weeks was $90.7 \%$ in the sorafenib group to TACE/RT and $23 \%$ in the combination group to sorafenib due to tumor progression. While, adverse events were similar between the 2 groups,. the safety and efficacy in a non-HBV population are not clear; and neither is the potential impact of not performing embolization due to concern for inducing liver dysfunction

\section{LRT + Immune Oncology (IO)}

Immunotherapies are being combined with LRT with the hope of improving the expected median OS in those with advanced HCC. s. ${ }^{140}$ The release of neoantigens induced by LRTassociated tumor necrosis may augment the response to immune check-point inhibitors. The first study used TACE or RFA in 32 patients (BCLC B/C with progressive disease at enrollment, 75\% sorafenib experienced) followed by tremelimab, an anti-CLLA-4 antibody, reported partial response in 26\%, TTP 7.4 months and overall survival 12.3 months. ${ }^{141}$ IO in earlier stage $\mathrm{HCC}$ is of concern for risk of rejection in the post-transplant setting.

\section{Supplementary Material}

Refer to Web version on PubMed Central for supplementary material.

\section{Acknowledgments}

GRANT SUPPORT: This material is based upon work supported by Cancer Prevention \& Research Institute of Texas grant (RP150587). The works is also supported in part by the Center for Gastrointestinal Development, Infection and Injury (NIDDK P30 DK 56338).

\section{References}

1. Singal AG, El-Serag HB. Hepatocellular carcinoma from epidemiology to prevention: translating knowledge into practice. Clinical gastroenterology and hepatology. 2015;13(12):2140-51. [PubMed: 26284591]

2. White DL, Thrift AP, Kanwal F, Davila J, El-Serag HB. Incidence of hepatocellular carcinoma in all 50 United States, from 2000 through 2012. Gastroenterology. 2017;152(4):812-20. e5. [PubMed: 27889576]

3. Armstrong GL, Wasley A, Simard EP, McQuillan GM, Kuhnert WL, Alter MJ. The prevalence of hepatitis C virus infection in the United States, 1999 through 2002. Annals of internal medicine. 2006;144(10):705-14. [PubMed: 16702586]

4. Kallwitz ER, Daviglus ML, Allison MA, Emory KT, Zhao L, Kuniholm MH, et al. Prevalence of suspected nonalcoholic fatty liver disease in Hispanic/Latino individuals differs by heritage. Clinical Gastroenterology and Hepatology. 2015;13(3):569-76. [PubMed: 25218670]

5. Mittal S, Sada YH, El-Serag HB, Kanwal F, Duan Z, Temple S, et al. Temporal trends of nonalcoholic fatty liver disease-related hepatocellular carcinoma in the veteran affairs population. Clinical Gastroenterology and Hepatology. 2015;13(3):594-601. e1. [PubMed: 25148760]

6. Chhatwal J, Kanwal F, Roberts MS, Dunn MA. Cost-effectiveness and budget impact of hepatitis C virus treatment with sofosbuvir and ledipasvir in the United States. Annals of internal medicine. 2015;162(6):397-406. [PubMed: 25775312]

7. El-Serag HB, Kramer J, Duan Z, Kanwal F. Racial differences in the progression to cirrhosis and hepatocellular carcinoma in $\mathrm{HCV}$-infected veterans. The American journal of gastroenterology. 2014;109(9):1427. [PubMed: 25070058] 
8. Kanwal F, Kramer JR, Ilyas J, Duan Z, El-Serag HB. HCV genotype 3 is associated with an increased risk of cirrhosis and hepatocellular cancer in a national sample of US Veterans with HCV. Hepatology. 2014;60(1):98-105. [PubMed: 24615981]

9. El-Serag HB. Epidemiology of viral hepatitis and hepatocellular carcinoma. Gastroenterology. 2012;142(6):1264-73. e1. [PubMed: 22537432]

10. Thrift AP, El-Serag HB, Kanwal F. Global epidemiology and burden of HCV infection and HCVrelated disease. Nature Reviews Gastroenterology and Hepatology. 2017;14(2):122. [PubMed: 27924080]

11. Reig M, Mariño Z, Perelló C, Iñarrairaegui M, Ribeiro A, Lens S, et al. Unexpected high rate of early tumor recurrence in patients with HCV-related HCC undergoing interferon-free therapy. Journal of hepatology. 2016;65(4):719-26. [PubMed: 27084592]

12. Huang AC, Mehta N, Dodge JL, Yao FY, Terrault NA. Direct-acting antivirals do not increase the risk of hepatocellular carcinoma recurrence after local-regional therapy or liver transplant waitlist dropout. Hepatology. 2018.

13. Ioannou GN, Green PK, Berry K. HCV eradication induced by direct-acting antiviral agents reduces the risk of hepatocellular carcinoma. Journal of hepatology. 2018;68(1):25-32.

14. Pol S Lack of evidence of an effect of Direct Acting Antivirals on the recurrence of hepatocellular carcinoma. J Hepatol. 2016;65:734-40. [PubMed: 27288051]

15. Waziry R, Hajarizadeh B, Grebely J, Amin J, Law M, Danta M, et al. Hepatocellular carcinoma risk following direct-acting antiviral HCV therapy: A systematic review, meta-analyses, and metaregression. Journal of hepatology. 2017;67(6):1204-12. [PubMed: 28802876]

16. Kanwal F, Kramer J, Asch SM, Chayanupatkul M, Cao Y, El-Serag HB. Risk of hepatocellular cancer in HCV patients treated with direct-acting antiviral agents. Gastroenterology. 2017;153(4): 996-1005. e1. [PubMed: 28642197]

17. Sarasin FP, Giostra E, Hadengue A. Cost-effectiveness of screening for detection of small hepatocellular carcinoma in western patients with Child-Pugh class A cirrhosis. The American journal of medicine. 1996;101(4):422-34. [PubMed: 8873514]

18. Arguedas MR, Chen VK, Eloubeidi MA, Fallon MB. Screening for hepatocellular carcinoma in patients with hepatitis $\mathrm{C}$ cirrhosis: a cost-utility analysis. The American journal of gastroenterology. 2003;98(3):679-90. [PubMed: 12650806]

19. Chayanupatkul M, Omino R, Mittal S, Kramer JR, Richardson P, Thrift AP, et al. Hepatocellular carcinoma in the absence of cirrhosis in patients with chronic hepatitis B virus infection. Journal of hepatology. 2017;66(2):355-62. [PubMed: 27693539]

20. Sung J, Tsoi K, Wong V, Li K, Chan H. Meta-analysis: treatment of hepatitis B infection reduces risk of hepatocellular carcinoma. Alimentary pharmacology \& therapeutics. 2008;28(9):1067-77. [PubMed: 18657133]

21. Wu C-Y, Lin J-T, Ho HJ, Su C-W, Lee T-Y, Wang S-Y, et al. Association of nucleos (1) ide analogue therapy with reduced risk of hepatocellular carcinoma in patients with chronic hepatitis B-a nationwide cohort study. Gastroenterology. 2014;147(1):143-51.e5. [PubMed: 24704525]

22. Wong GLH, Chan HLY, Mak CWH, Lee SKY, Ip ZMY, Lam ATH, et al. Entecavir treatment reduces hepatic events and deaths in chronic hepatitis B patients with liver cirrhosis. Hepatology. 2013;58(5):1537-47. [PubMed: 23389810]

23. Wong VW-S, Chan SL, Mo F, Chan T-C, Loong HH-F, Wong GL-H, et al. Clinical scoring system to predict hepatocellular carcinoma in chronic hepatitis B carriers. Journal of clinical oncology. 2010;28(10):1660-5. [PubMed: 20194845]

24. Yuen M-F, Tanaka Y, Fong DY-T, Fung J, Wong DK-H, Yuen JC-H, et al. Independent risk factors and predictive score for the development of hepatocellular carcinoma in chronic hepatitis B. Journal of hepatology. 2009;50(1):80-8. [PubMed: 18977053]

25. Yang H-I, Yuen M-F, Chan HL-Y, Han K-H, Chen P-J, Kim D-Y, et al. Risk estimation for hepatocellular carcinoma in chronic hepatitis B (REACH-B): development and validation of a predictive score. The lancet oncology. 2011;12(6):568-74. [PubMed: 21497551]

26. Kim WR, Loomba R, Berg T, Aguilar Schall RE, Yee LJ, Dinh PV, et al. Impact of long-term tenofovir disoproxil fumarate on incidence of hepatocellular carcinoma in patients with chronic hepatitis B. Cancer. 2015;121(20):3631-8. [PubMed: 26177866] 
27. Ahn J, Lim JK, Lee HM, Lok AS, Nguyen M, Pan CQ, et al. Lower observed hepatocellular carcinoma incidence in chronic hepatitis B patients treated With entecavir: results of the ENUMERATE study. Nature Publishing Group; 2016.

28. Hsu Y-C, Wu C-Y, Lane H-Y, Chang C-Y, Tai C-M, Tseng C-H, et al. Determinants of hepatocellular carcinoma in cirrhotic patients treated with nucleos (1) ide analogues for chronic hepatitis B. Journal of Antimicrobial Chemotherapy. 2014;69(7):1920-7. [PubMed: 24576950]

29. Papatheodoridis GV, Dalekos GN, Yurdaydin C, Buti M, Goulis J, Arends P, et al. Incidence and predictors of hepatocellular carcinoma in Caucasian chronic hepatitis B patients receiving entecavir or tenofovir. Journal of hepatology. 2015;62(2):363-70. [PubMed: 25195548]

30. Raffetti E, Fattovich G, Donato F. Incidence of hepatocellular carcinoma in untreated subjects with chronic hepatitis B: a systematic review and meta-analysis. Liver International. 2016;36(9):1239_ 51. [PubMed: 27062182]

31. Chen C-J, Yang H-I, Su J, Jen C-L, You S-L, Lu S-N, et al. Risk of hepatocellular carcinoma across a biological gradient of serum hepatitis B virus DNA level. Jama. 2006;295(1):65-73. [PubMed: 16391218]

32. Yang H-I, Lu S-N, Liaw Y-F, You S-L, Sun C-A, Wang L-Y, et al. Hepatitis B e antigen and the risk of hepatocellular carcinoma. New England Journal of Medicine. 2002;347(3):168-74. [PubMed: 12124405]

33. Tseng TC, Liu CJ, Yang HC, Su TH, Wang CC, Chen CL, et al. High levels of hepatitis B surface antigen increase risk of hepatocellular carcinoma in patients with low HBV load. Gastroenterology. 2012;142(5):1140-9. e3. [PubMed: 22333950]

34. Hsu YC, Ho HJ, Lee TY, Huang YT, Wu MS, Lin JT, et al. Temporal trend and risk determinants of hepatocellular carcinoma in chronic hepatitis B patients on entecavir or tenofovir. Journal of viral hepatitis. 2018;25(5):543-51. [PubMed: 29193536]

35. Kim MN, Hwang SG, Rim KS, Kim BK, Park JY, Kim DY, et al. Validation of Page-b model in Asian chronic hepatitis B patients receiving entecavir or tenofovir. Liver International. 2017.

36. Papatheodoridis GV, Idilman R, Dalekos GN, Buti M, Chi H, van Boemmel F, et al. The risk of hepatocellular carcinoma is decreasing after the first 5 years of entecavir or tenofovir in Caucasians with chronic hepatitis B. Hepatology. 2017.

37. Lok AS, McMahon BJ. Chronic hepatitis B: update 2009. Hepatology. 2009;50(3):661-2. [PubMed: 19714720]

38. Gordon SC, Lamerato LE, Rupp LB, Li J, Holmberg SD, Moorman AC, et al. Antiviral therapy for chronic hepatitis B virus infection and development of hepatocellular carcinoma in a US population. Clinical Gastroenterology and Hepatology. 2014;12(5):885-93. [PubMed: 24107395]

39. Mittal S, Kramer JR, Omino R, Chayanupatkul M, Richardson PA, El-Serag HB, et al. Role of Age and Race in the Risk of Hepatocellular Carcinoma in Veterans With Hepatitis B Virus Infection. Clinical Gastroenterology and Hepatology. 2017.

40. Kew E, Marcus R. Some characteristics of Mozambican Shangaans with primary hepatocellular cancer. South African Medical Journal. 1977;51(10):306-9. [PubMed: 66757]

41. Kew MC, Macerollo P. Effect of age on the etiologic role of the hepatitis B virus in hepatocellular carcinoma in blacks. Gastroenterology. 1988;94(2):439-42. [PubMed: 2446950]

42. Yang JD, Mohamed EA, Aziz AOA, Shousha HI, Hashem MB, Nabeel MM, et al. Characteristics, management, and outcomes of patients with hepatocellular carcinoma in Africa: a multicountry observational study from the Africa Liver Cancer Consortium. The Lancet Gastroenterology \& Hepatology. 2017;2(2):103-11. [PubMed: 28403980]

43. Stepanova M, De Avila L, Afendy M, Younossi I, Pham H, Cable R, et al. Direct and indirect economic burden of chronic liver disease in the United States. Clinical Gastroenterology and Hepatology. 2017;15(5):759-66. e5. [PubMed: 27464590]

44. Williams CD, Stengel J, Asike MI, Torres DM, Shaw J, Contreras M, et al. Prevalence of nonalcoholic fatty liver disease and nonalcoholic steatohepatitis among a largely middle-aged population utilizing ultrasound and liver biopsy: a prospective study. Gastroenterology. 2011;140(1):124-31. [PubMed: 20858492] 
45. Ahmed A, Wong RJ, Harrison SA. Nonalcoholic fatty liver disease review: diagnosis, treatment, and outcomes. Clinical Gastroenterology and Hepatology. 2015;13(12):2062-70. [PubMed: 26226097]

46. Rich NE, Oji S, Mufti AR, Browning JD, Parikh ND, Odewole M, et al. Racial and Ethnic Disparities in Nonalcoholic Fatty Liver Disease Prevalence, Severity, and Outcomes in the United States: A Systematic Review and Meta-analysis. Clinical Gastroenterology and Hepatology. 2017.

47. Wong RJ, Cheung R, Ahmed A. Nonalcoholic steatohepatitis is the most rapidly growing indication for liver transplantation in patients with hepatocellular carcinoma in the US. Hepatology. 2014;59(6):2188-95. [PubMed: 24375711]

48. White DL, Kanwal F, El-Serag HB. Association between nonalcoholic fatty liver disease and risk for hepatocellular cancer, based on systematic review. Clinical gastroenterology and hepatology. 2012;10(12):1342-59. e2. [PubMed: 23041539]

49. Mittal S, El-Serag HB, Sada YH, Kanwal F, Duan Z, Temple S, et al. Hepatocellular carcinoma in the absence of cirrhosis in United States veterans is associated with nonalcoholic fatty liver disease. Clinical Gastroenterology and Hepatology. 2016;14(1):124-31. e1. [PubMed: 26196445]

50. El-Serag HB, Hampel H, Javadi F. The association between diabetes and hepatocellular carcinoma: a systematic review of epidemiologic evidence. Clinical Gastroenterology and Hepatology. 2006;4(3):369-80. [PubMed: 16527702]

51. Chen J, Han Y, Xu C, Xiao T, Wang B. Effect of type 2 diabetes mellitus on the risk for hepatocellular carcinoma in chronic liver diseases: a meta-analysis of cohort studies. European Journal of Cancer Prevention. 2015;24(2):89-99. [PubMed: 24809655]

52. Singh S, Singh PP, Singh AG, Murad MH, Sanchez W. Anti-diabetic medications and the risk of hepatocellular cancer: a systematic review and meta-analysis. The American journal of gastroenterology. 2013;108(6):881. [PubMed: 23381014]

53. Chen H-P, Shieh J-J, Chang C-C, Chen T-T, Lin J-T, Wu M-S, et al. Metformin decreases hepatocellular carcinoma risk in a dose-dependent manner: population-based and in vitro studies. Gut. 2012:gutjnl-2011-301708.

54. Donadon V, Balbi M, Mas MD, Casarin P, Zanette G. Metformin and reduced risk of hepatocellular carcinoma in diabetic patients with chronic liver disease. Liver international. 2010;30(5):750-8. [PubMed: 20331505]

55. Hassan MM, Curley SA, Li D, Kaseb A, Davila M, Abdalla EK, et al. Association of diabetes duration and diabetes treatment with the risk of hepatocellular carcinoma. Cancer. 2010;116(8): 1938-46. [PubMed: 20166205]

56. Flemming JA, Yang JD, Vittinghoff E, Kim WR, Terrault NA. Risk prediction of hepatocellular carcinoma in patients with cirrhosis: the ADRESS-HCC risk model. Cancer. 2014;120(22):348593. [PubMed: 25042049]

57. Saunders D, Seidel D, Allison M, Lyratzopoulos G. Systematic review: the association between obesity and hepatocellular carcinoma-epidemiological evidence. Alimentary pharmacology \& therapeutics. 2010;31(10):1051-63. [PubMed: 20175765]

58. Schlesinger S, Aleksandrova K, Pischon T, Jenab M, Fedirko V, Trepo E, et al. Diabetes mellitus, insulin treatment, diabetes duration, and risk of biliary tract cancer and hepatocellular carcinoma in a European cohort. Annals of oncology. 2013;24(9):2449-55. [PubMed: 23720454]

59. Welzel TM, Graubard BI, Quraishi S, Zeuzem S, Davila JA, El-Serag HB, et al. Populationattributable fractions of risk factors for hepatocellular carcinoma in the United States. The American journal of gastroenterology. 2013;108(8):1314. [PubMed: 23752878]

60. Younossi Z, Stepanova M, Ong JP, Jacobson IM, Bugianesi E, Duseja A, et al. Non-alcoholic Steatohepatitis is the Fastest Growing Cause of Hepatocellular Carcinoma in Liver Transplant Candidates. Clinical Gastroenterology and Hepatology. 2018.

61. El-Serag HB, Kanwal F. Obesity and hepatocellular carcinoma: hype and reality. Hepatology. 2014;60(3):779-81. [PubMed: 24753107]

62. Bruix J, Sherman M. Management of hepatocellular carcinoma: an update. Hepatology. 2011;53(3):1020-2. [PubMed: 21374666] 
63. Marrero JA, Kulik LM, Sirlin C, Zhu AX, Finn RS, Abecassis MM, et al. Diagnosis, staging and management of hepatocellular carcinoma: 2018 practice guidance by the American Association for the Study of Liver Diseases. Hepatology. 2018.

64. Ronot M, Fouque O, Esvan M, Lebigot J, Aubé C, Vilgrain V. Comparison of the accuracy of AASLD and LI-RADS criteria for the non-invasive diagnosis of HCC smaller than $3 \mathrm{~cm}$. Journal of hepatology. 2017.

65. Sirlin CB, Kielar AZ, Tang A, Bashir MR. LI-RADS: a glimpse into the future. Abdominal Radiology. 2018:1-6. [PubMed: 29282489]

66. Silva MA, Hegab B, Hyde C, Guo B, Buckels JA, Mirza DF. Needle track seeding following biopsy of liver lesions in the diagnosis of hepatocellular cancer: a systematic review and metaanalysis. Gut. 2008;57(11):1592-6. [PubMed: 18669577]

67. Maturen KE, Nghiem HV, Marrero JA, Hussain HK, Higgins EG, Fox GA, et al. Lack of tumor seeding of hepatocellular carcinoma after percutaneous needle biopsy using coaxial cutting needle technique. American Journal of Roentgenology. 2006;187(5):1184-7. [PubMed: 17056903]

68. Forner A, Vilana R, Ayuso C, Bianchi L, Solé M, Ayuso JR, et al. Diagnosis of hepatic nodules 20 $\mathrm{mm}$ or smaller in cirrhosis: prospective validation of the noninvasive diagnostic criteria for hepatocellular carcinoma. Hepatology. 2008;47(1):97-104. [PubMed: 18069697]

69. Saffroy R, Pham P, Reffas M, Takka M, Lemoine A, Debuire B. New perspectives and strategy research biomarkers for hepatocellular carcinoma. Clinical Chemical Laboratory Medicine. 2007;45(9):1169-79.

70. Llovet JM, Brú C, Bruix J. Prognosis of Hepatocellular Carcinoma: The BCLC Staging Classification. Semin Liver Dis. 1999;19(03):329-38. [PubMed: 10518312]

71. Khalaf N, Ying J, Mittal S, Temple S, Kanwal F, Davila J, et al. Natural history of untreated hepatocellular carcinoma in a US cohort and the role of cancer surveillance. Clinical Gastroenterology and Hepatology. 2017;15(2):273-81.e1. [PubMed: 27521507]

72. Giannini EG, Farinati F, Ciccarese F, Pecorelli A, Rapaccini GL, Di Marco M, et al. Prognosis of untreated hepatocellular carcinoma. Hepatology. 2015;61(1):184-90. [PubMed: 25234419]

73. Yau T, Tang VY, Yao T-J, Fan S-T, Lo C-M, Poon RT. Development of Hong Kong Liver Cancer staging system with treatment stratification for patients with hepatocellular carcinoma. Gastroenterology. 2014;146(7):1691-700. e3. [PubMed: 24583061]

74. DuBay D, Sandroussi C, Sandhu L, Cleary S, Guba M, Cattral MS, et al. Liver transplantation for advanced hepatocellular carcinoma using poor tumor differentiation on biopsy as an exclusion criterion. Annals of surgery. 2011;253(1):166-72. [PubMed: 21294289]

75. Sapisochin G, Goldaracena N, Laurence JM, Dib M, Barbas A, Ghanekar A, et al. The extended Toronto criteria for liver transplantation in patients with hepatocellular carcinoma: A prospective validation study. Hepatology. 2016;64(6):2077-88. [PubMed: 27178646]

76. Zucman-Rossi J, Villanueva A, Nault J-C, Llovet JM. Genetic landscape and biomarkers of hepatocellular carcinoma. Gastroenterology. 2015;149(5):1226-39. e4. [PubMed: 26099527]

77. Pinyol R, Montal R, Takayama T, Chau G-Y, Mazzaferro V, Roayaie S, et al. Molecular predictors of recurrence prevention with sorafenib as adjuvant therapy in hepatocellular carcinoma: Biomarker study of the STORM phase III trial. Journal of Hepatology. 2017;66(1):S12-S3.

78. Sia D, Jiao Y, Martinez-Quetglas I, Kuchuk O, Villacorta-Martin C, de Moura MC, et al. Identification of an immune-specific class of hepatocellular carcinoma, based on molecular features. Gastroenterology. 2017;153(3):812-26. [PubMed: 28624577]

79. Hameed B, Mehta N, Sapisochin G, Roberts JP, Yao FY. Alpha-fetoprotein level> $1000 \mathrm{ng} / \mathrm{mL}$ as an exclusion criterion for liver transplantation in patients with hepatocellular carcinoma meeting the Milan criteria. Liver Transplantation. 2014;20(8):945-51. [PubMed: 24797281]

80. Duvoux C, Roudot-Thoraval F, Decaens T, Pessione F, Badran H, Piardi T, et al. Liver transplantation for hepatocellular carcinoma: a model including a-fetoprotein improves the performance of Milan criteria. Gastroenterology. 2012;143(4):986-94. e3. [PubMed: 22750200]

81. Toso C, Asthana S, Bigam DL, Shapiro A, Kneteman NM. Reassessing selection criteria prior to liver transplantation for hepatocellular carcinoma utilizing the Scientific Registry of Transplant Recipients database. Hepatology. 2009;49(3):832-8. [PubMed: 19152426] 
82. Giard J-M, Mehta N, Dodge JL, Roberts JP, Yao FY. Alpha-Fetoprotein Slope> 7.5 ng/mL per Month Predicts Microvascular Invasion and Tumor Recurrence After Liver Transplantation for Hepatocellular Carcinoma. Transplantation. 2018;102(5):816-22. [PubMed: 29505494]

83. Berry K, Ioannou GN. Serum alpha-fetoprotein level independently predicts posttransplant survival in patients with hepatocellular carcinoma. Liver Transplantation. 2013;19(6):634-45. [PubMed: 23536495]

84. Xu Z-G, Ye C-J, Liu L-X, Wu G, Zhao Z-X, Wang Y-Z, et al. The pretransplant neutrophillymphocyte ratio as a new prognostic predictor after liver transplantation for hepatocellular cancer: a systematic review and meta-analysis. Biomarkers in medicine. 2018(0).

85. Lee J-H, Cho Y, Kim HY, Cho EJ, Lee DH, Yu SJ, et al. Serum tumor markers provide refined prognostication in selecting liver transplantation candidate for hepatocellular carcinoma patients beyond the Milan criteria. Annals of surgery. 2016;263(5):842-50. [PubMed: 26779979]

86. Halazun KJ, Najjar M, Abdelmessih RM, Samstein B, Griesemer AD, Guarrera JV, et al. Recurrence after liver transplantation for hepatocellular carcinoma: a new MORAL to the story. Annals of surgery. 2017;265(3):557-64. [PubMed: 27611615]

87. Lai Q, Nicolini D, Nunez MI, Iesari S, Goffette P, Agostini A, et al. A Novel Prognostic Index in Patients With Hepatocellular Cancer Waiting for Liver Transplantation: Time-Radiologicalresponse-Alpha-fetoprotein-INflammation (TRAIN) Score. Annals of surgery. 2016;264(5):78796. [PubMed: 27429025]

88. Lo CM, Ngan H, Tso WK, Liu CL, Lam CM, Poon RTP, et al. Randomized controlled trial of transarterial lipiodol chemoembolization for unresectable hepatocellular carcinoma. Hepatology. 2002;35(5):1164-71. [PubMed: 11981766]

89. Llovet JM, Real MI, Montaña X, Planas R, Coll S, Aponte J, et al. Arterial embolisation or chemoembolisation versus symptomatic treatment in patients with unresectable hepatocellular carcinoma: a randomised controlled trial. The Lancet. 2002;359(9319):1734-9.

90. Bolondi L, Burroughs A, Dufour J-F, Galle PR, Mazzaferro V, Piscaglia F, et al., editors. Heterogeneity of patients with intermediate (BCLC B) Hepatocellular Carcinoma: proposal for a subclassification to facilitate treatment decisions Seminars in liver disease; 2012: Thieme Medical Publishers.

91. Burrel M, Reig M, Forner A, Barrufet M, de Lope CR, Tremosini S, et al. Survival of patients with hepatocellular carcinoma treated by transarterial chemoembolisation (TACE) using Drug Eluting Beads. Implications for clinical practice and trial design. Journal of hepatology. 2012;56(6):13305. [PubMed: 22314428]

92. Giannini EG, Bucci L, Garuti F, Brunacci M, Lenzi B, Valente M, et al. Patients with advanced hepatocellular carcinoma need a personalized management: A lesson from clinical practice. Hepatology. 2018;67(5):1784-96. [PubMed: 29159910]

93. Reig M, Rimola J, Torres F, Darnell A, Rodriguez-Lope C, Forner A, et al. Postprogression survival of patients with advanced hepatocellular carcinoma: Rationale for second-line trial design. Hepatology. 2013;58(6):2023-31. [PubMed: 23787822]

94. Bruix J, Merle P, Granito A, Huang Y-H, Bodoky G, Pracht M, et al. Survival by pattern of tumor progression during prior sorafenib (SOR) treatment in patients with hepatocellular carcinoma (HCC) in the phase III RESORCE trial comparing second-line treatment with regorafenib (REG) or placebo. Journal of Clinical Oncology. 2017;35(4_suppl):229-.

95. Livraghi T, Meloni F, Di Stasi M, Rolle E, Solbiati L, Tinelli C, et al. Sustained complete response and complications rates after radiofrequency ablation of very early hepatocellular carcinoma in cirrhosis: is resection still the treatment of choice? Hepatology. 2008;47(1):82-9. [PubMed: 18008357]

96. Roayaie S, Jibara G, Tabrizian P, Park JW, Yang J, Yan L, et al. The role of hepatic resection in the treatment of hepatocellular cancer. Hepatology. 2015;62(2):440-51. [PubMed: 25678263]

97. Mehta N, Sarkar M, Dodge JL, Fidelman N, Roberts JP, Yao FY. Intention to treat outcome of T1 hepatocellular carcinoma with the "wait and not ablate" approach until meeting T2 criteria for liver transplant listing. Liver Transplantation. 2016;22(2):178-87. [PubMed: 26479422] 
98. Heimbach JK, Kulik LM, Finn RS, Sirlin CB, Abecassis MM, Roberts LR, et al. Aasld guidelines for the treatment of hepatocellular carcinoma. Hepatology. 2018;67(1):358-80. [PubMed: 28130846]

99. Vitale A, Peck-Radosavljevic M, Giannini EG, Vibert E, Sieghart W, Van Poucke S, et al. Personalized treatment of patients with very early hepatocellular carcinoma. Journal of hepatology. 2017;66(2):412-23. [PubMed: 27677712]

100. Ferrer-Fàbrega J, Forner A, Liccioni A, Miquel R, Molina V, Navasa M, et al. Prospective validation of ab initio liver transplantation in hepatocellular carcinoma upon detection of risk factors for recurrence after resection. Hepatology. 2016;63(3):839-49. [PubMed: 26567038]

101. Bruix J, Llovet JM. Prognostic prediction and treatment strategy in hepatocellular carcinoma. Hepatology. 2002;35(3):519-24. [PubMed: 11870363]

102. Abulkhir A, Limongelli P, Healey AJ, Damrah O, Tait P, Jackson J, et al. Preoperative portal vein embolization for major liver resection: a meta-analysis. Annals of surgery. 2008;247(1):49-57. [PubMed: 18156923]

103. Vouche M, Lewandowski RJ, Atassi R, Memon K, Gates VL, Ryu RK, et al. Radiation lobectomy: time-dependent analysis of future liver remnant volume in unresectable liver cancer as a bridge to resection. Journal of hepatology. 2013;59(5):1029-36. [PubMed: 23811303]

104. Teo JY, Allen JC, Ng DC, Choo SP, Tai DW, Chang JP, et al. A systematic review of contralateral liver lobe hypertrophy after unilobar selective internal radiation therapy with Y90. HPB. 2015.

105. Bruix J, Takayama T, Mazzaferro V, Chau G-Y, Yang J, Kudo M, et al. Adjuvant sorafenib for hepatocellular carcinoma after resection or ablation (STORM): a phase 3, randomised, doubleblind, placebo-controlled trial. The lancet oncology. 2015;16(13):1344-54. [PubMed: 26361969]

106. Camma C, Cabibbo G, Craxì A. Direct antiviral agents and risk for HCC early recurrence: much ado about nothing. Journal of hepatology. 2016;65(4):861-2. [PubMed: 27255578]

107. Kokudo T, Hasegawa K, Matsuyama Y, Takayama T, Izumi N, Kadoya M, et al. Survival benefit of liver resection for hepatocellular carcinoma associated with portal vein invasion. Journal of hepatology. 2016;65(5):938-43. [PubMed: 27266618]

108. Kulik L, Heimbach JK, Zaiem F, Almasri J, Prokop LJ, Wang Z, et al. Therapies for patients with hepatocellular carcinoma awaiting liver transplantation: A systematic review and meta-analysis. Hepatology. 2018;67(1):381-400. [PubMed: 28859222]

109. Salem R, Gordon AC, Mouli S, Hickey R, Kallini J, Gabr A, et al. Y90 radioembolization significantly prolongs time to progression compared with chemoembolization in patients with hepatocellular carcinoma. Gastroenterology. 2016;151(6):1155-63. e2. [PubMed: 27575820]

110. Toso C, Mentha G, Kneteman NM, Majno P. The place of downstaging for hepatocellular carcinoma. Journal of hepatology. 2010;52(6):930-6. [PubMed: 20385428]

111. Parikh ND, Waljee AK, Singal AG. Downstaging hepatocellular carcinoma: a systematic review and pooled analysis. Liver Transplantation. 2015;21(9):1142-52. [PubMed: 25981135]

112. Yao FY, Mehta N, Flemming J, Dodge J, Hameed B, Fix O, et al. Downstaging of hepatocellular cancer before liver transplant: long-term outcome compared to tumors within Milan criteria. Hepatology. 2015;61(6):1968-77. [PubMed: 25689978]

113. Mehta N, Guy J, Frenette CT, Dodge JL, Osorio RW, Minteer WB, et al. Excellent Outcomes of Liver Transplantation Following Down Staging of Hepatocellular Carcinoma to Within Milan Criteria-a Multi-Center Study. Clinical Gastroenterology and Hepatology. 2017.

114. Sapisochin G, Barry A, Doherty M, Fischer S, Goldaracena N, Rosales R, et al. Stereotactic body radiotherapy vs. TACE or RFA as a bridge to transplant in patients with hepatocellular carcinoma. An intention-to-treat analysis. Journal of hepatology. 2017;67(1):92-9. [PubMed: 28257902]

115. Salem R, Gabr A, Riaz A, Mora R, Ali R, Abecassis M, et al. Institutional Decision to Adopt Y90 as Primary Treatment for HCC Informed by a 1,000-patient 15-year Experience. Hepatology. 2017.

116. Garin E, Lenoir L, Edeline J, Laffont S, Mesbah H, Porée P, et al. Boosted selective internal radiation therapy with 90 Y-loaded glass microspheres (B-SIRT) for hepatocellular carcinoma patients: a new personalized promising concept. European journal of nuclear medicine and molecular imaging. 2013;40(7):1057-68. [PubMed: 23613103] 
117. Garin E, Rolland Y, Pracht M, Le Sourd S, Laffont S, Mesbah H, et al. High impact of macroaggregated albumin-based tumour dose on response and overall survival in hepatocellular carcinoma patients treated with 90Y-loaded glass microsphere radioembolization. Liver International. 2017;37(1):101-10. [PubMed: 27514012]

118. Spreafico C, Sposito C, Vaiani M, Cascella T, Bhoori S, Morosi C, et al. Development of a prognostic score to predict response to yttrium-90 radioembolization for hepatocellular carcinoma with portal vein invasion. Journal of hepatology. 2018.

119. Salem R, Lewandowski RJ, Gates VL, Nutting CW, Murthy R, Rose SC, et al. Research reporting standards for radioembolization of hepatic malignancies. Journal of Vascular and Interventional Radiology. 2011;22(3):265-78. [PubMed: 21353979]

120. Kulik LM, Carr BI, Mulcahy MF, Lewandowski RJ, Atassi B, Ryu RK, et al. Safety and efficacy of $90 \mathrm{Y}$ radiotherapy for hepatocellular carcinoma with and without portal vein thrombosis. Hepatology. 2008;47(1):71-81. [PubMed: 18027884]

121. Mazzaferro V, Sposito C, Bhoori S, Romito R, Chiesa C, Morosi C, et al. Yttrium-90 radioembolization for intermediate-advanced hepatocellular carcinoma: a phase 2 study. Hepatology. 2013;57(5):1826-37. [PubMed: 22911442]

122. Chen Q-W, Ying H-F, Gao S, Shen Y-H, Meng Z-Q, Chen H, et al. Radiofrequency ablation plus chemoembolization versus radiofrequency ablation alone for hepatocellular carcinoma: A systematic review and meta-analysis. Clinics and research in hepatology and gastroenterology. 2016;40(3):309-14. [PubMed: 26428660]

123. lezzi R, Pompili M, La Torre MF, Campanale MC, Montagna M, Saviano A, et al. Radiofrequency ablation plus drug-eluting beads transcatheter arterial chemoembolization for the treatment of single large hepatocellular carcinoma. Digestive and Liver Disease. 2015;47(3):2428. [PubMed: 25577299]

124. Zhang L, Hu P, Chen X, Bie P. Transarterial chemoembolization (TACE) plus sorafenib versus TACE for intermediate or advanced stage hepatocellular carcinoma: a meta-analysis. PloS one. 2014;9(6):e100305. [PubMed: 24945380]

125. Kudo M, Arizumi T. Transarterial Chemoembolization in Combination with a Molecular Targeted Agent: Lessons Learned from Negative Trials (Post-TACE, BRISK-TA, SPACE, ORIENTAL, and TACE-2). Oncology. 2017;93(Suppl. 1):127-34.

126. Kudo M, Ueshima K, Ikeda M, Torimura T, Tanabe N, Aikata H, et al. Randomized, open label, multicenter, phase II trial comparing transarterial chemoembolization (TACE) plus sorafenib with TACE alone in patients with hepatocellular carcinoma (HCC): TACTICS trial. American Society of Clinical Oncology; 2018.

127. European Association For The Study Of The Liver. EASL-EORTC clinical practice guidelines: management of hepatocellular carcinoma. Journal of hepatology. 2012;56(4):908-43. [PubMed: 22424438]

128. Llovet JM, Ricci S, Mazzaferro V, Hilgard P, Gane E, Blanc J-F, et al. Sorafenib in advanced hepatocellular carcinoma. New England journal of medicine. 2008;359(4):378-90. [PubMed: 18650514]

129. Bruix J, Cheng A-L, Meinhardt G, Nakajima K, De Sanctis Y, Llovet J. Prognostic factors and predictors of sorafenib benefit in patients with hepatocellular carcinoma: Analysis of two phase III studies. Journal of hepatology. 2017;67(5):999-1008. [PubMed: 28687477]

130. Kudo M, Finn RS, Qin S, Han K-H, Ikeda K, Piscaglia F, et al. Lenvatinib versus sorafenib in first- line treatment of patients with unresectable hepatocellular carcinoma: a randomised phase 3 non-inferiority trial. The Lancet. 2018;391(10126):1163-73.

131. Bruix J, Qin S, Merle P, Granito A, Huang Y-H, Bodoky G, et al. Regorafenib for patients with hepatocellular carcinoma who progressed on sorafenib treatment (RESORCE): a randomised, double blind, placebo-controlled, phase 3 trial. The Lancet. 2017;389(10064):56-66.

132. Finn RS, Merle P, Granito A, Huang Y-H, Bodoky G, Pracht M, et al. Outcomes with sorafenib (SOR) followed by regorafenib (REG) or placebo (PBO) for hepatocellular carcinoma (HCC): Results of the international, randomized phase 3 RESORCE trial. American Society of Clinical Oncology; 2017. 
133. El-Khoueiry AB, Sangro B, Yau T, Crocenzi TS, Kudo M, Hsu C, et al. Nivolumab in patients with advanced hepatocellular carcinoma (CheckMate 040): an open-label, non-comparative, phase 1/2 dose escalation and expansion trial. The Lancet. 2017;389(10088):2492-502.

134. Abou-Alfa GK, Meyer T, Cheng A-L, El-Khoueiry AB, Rimassa L, Ryoo B-Y, et al. Cabozantinib $(\mathrm{C})$ versus placebo $(\mathrm{P})$ in patients (pts) with advanced hepatocellular carcinoma (HCC) who have received prior sorafenib: Results from the randomized phase III CELESTIAL trial. American Society of Clinical Oncology; 2018.

135. Ricke J, Sangro B, Amthauer H, Bargellini I, Bartenstein P, De Toni E, et al. The impact of combining Selective Internal Radiation Therapy (SIRT) with Sorafenib on overall survival in patients with advanced hepatocellular carcinoma: The Soramic trial palliative cohort. Journal of Hepatology. 2018;68:S102.

136. Vilgrain V, Pereira H, Assenat E, Guiu B, Ilonca AD, Pageaux G-P, et al. Efficacy and safety of selective internal radiotherapy with yttrium-90 resin microspheres compared with sorafenib in locally advanced and inoperable hepatocellular carcinoma (SARAH): an open-label randomised controlled phase 3 trial. The Lancet Oncology. 2017;18(12):1624-36. [PubMed: 29107679]

137. Chow PH, Gandhi M, Group A-PHCT. Phase III multi-centre open-label randomized controlled trial of selective internal radiation therapy (SIRT) versus sorafenib in locally advanced hepatocellular carcinoma: The SIRveNIB study. American Society of Clinical Oncology; 2017.

138. Huo YR, Eslick GD. Transcatheter arterial chemoembolization plus radiotherapy compared with chemoembolization alone for hepatocellular carcinoma: a systematic review and meta-analysis. JAMA oncology. 2015;1(6):756-65. [PubMed: 26182200]

139. Yoon SM, Ryoo B-Y, Lee SJ, Kim JH, Shin JH, An JH, et al. Efficacy and Safety of Transarterial Chemoembolization Plus External Beam Radiotherapy vs Sorafenib in Hepatocellular Carcinoma With Macroscopic Vascular Invasion: A Randomized Clinical Trial. JAMA oncology. 2018;4(5): 661-9. [PubMed: 29543938]

140. Kudo M Immuno-Oncology in Hepatocellular Carcinoma: 2017 Update. Oncology. 2017;93(Suppl. 1):147-59. [PubMed: 29258079]

141. Duffy AG, Ulahannan SV, Makorova-Rusher O, Rahma O, Wedemeyer H, Pratt D, et al. Tremelimumab in combination with ablation in patients with advanced hepatocellular carcinoma. Journal of hepatology. 2017;66(3):545-51. [PubMed: 27816492] 


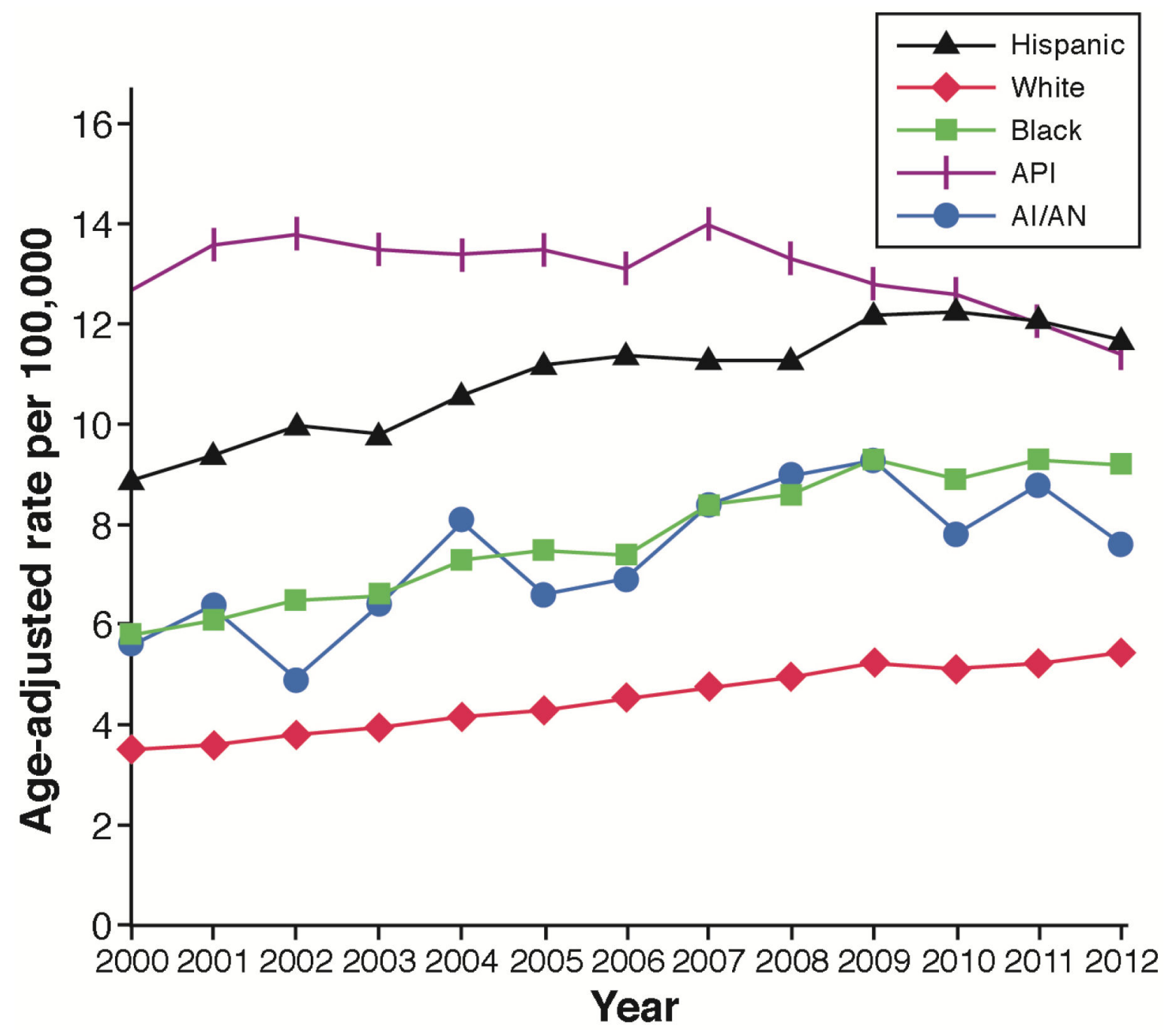

FIGURE 1.

Yearly age adjusted incidence rates of HCC in United States between 2000 and 2012 broken by race and ethnicity. Adopted from ref \# 2 


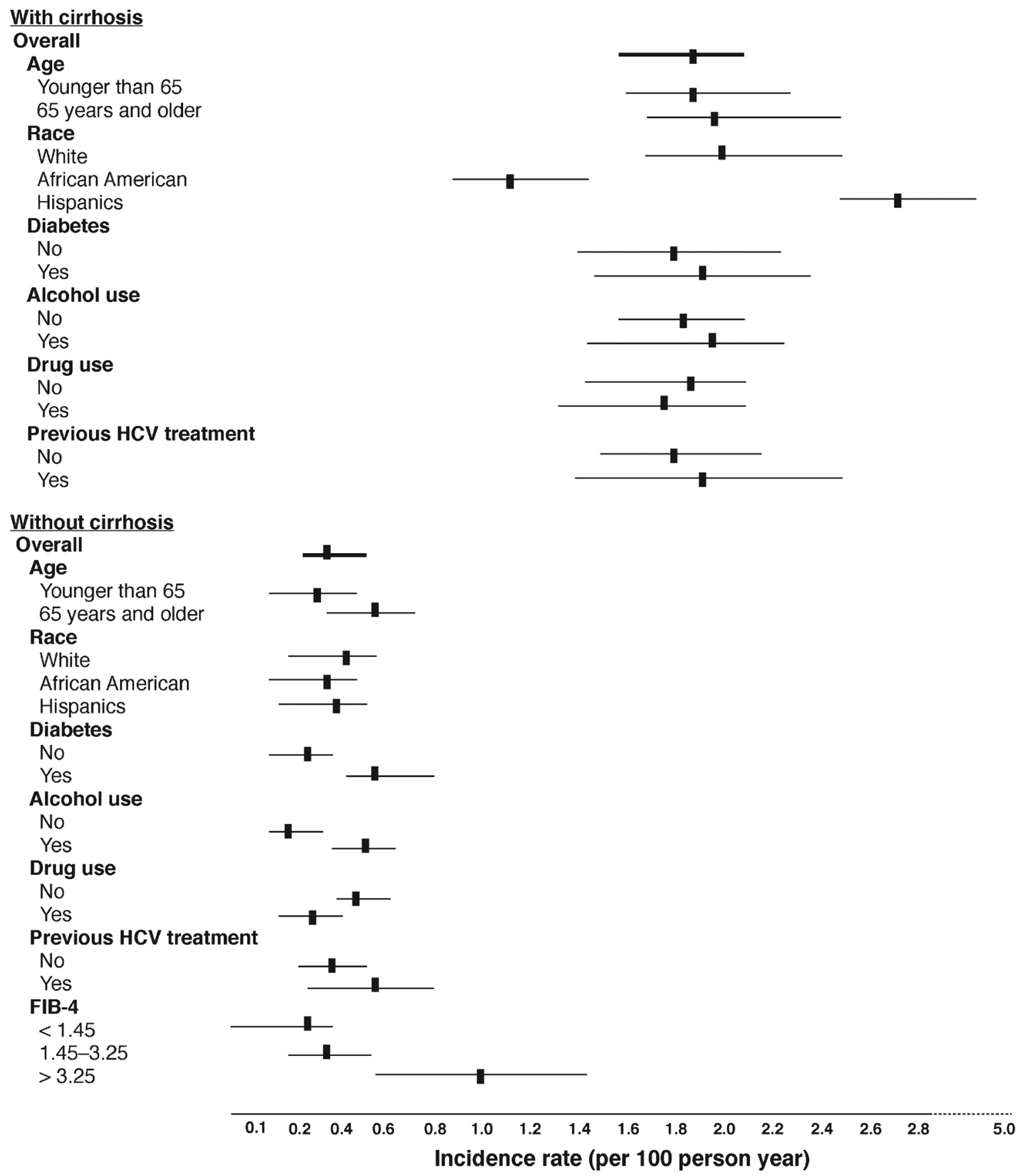

FIGURE 2.

The cumulative incidence and determinates of HCC following DAA-related SVR among VA patients with HCV. The incidence rates are shown according to several demographic and clinical features for patients with and without cirrhosis at baseline. Adopted from ref \# 16 


\begin{tabular}{|lr|}
\hline Variable & Risk score \\
\hline Cirrhosis & \\
No cirrhosis & 0 \\
Cirrhosis with age $<40 \mathrm{yr}$ & 10 \\
Cirrhosis with age $\geq 40 \mathrm{yr}$ & 6 \\
\hline Age & \\
Age $<40 \mathrm{yr}$ & 0 \\
Age 40-49 yr & 5 \\
Age 50-59 yr & 8 \\
Age 50 yr or older & 10 \\
\hline Gender & \\
Female sex & 0 \\
Male sex & 2 \\
\hline Diabetes mellitus & \\
Not diabetic & 0 \\
Diabetic & 1 \\
\hline
\end{tabular}

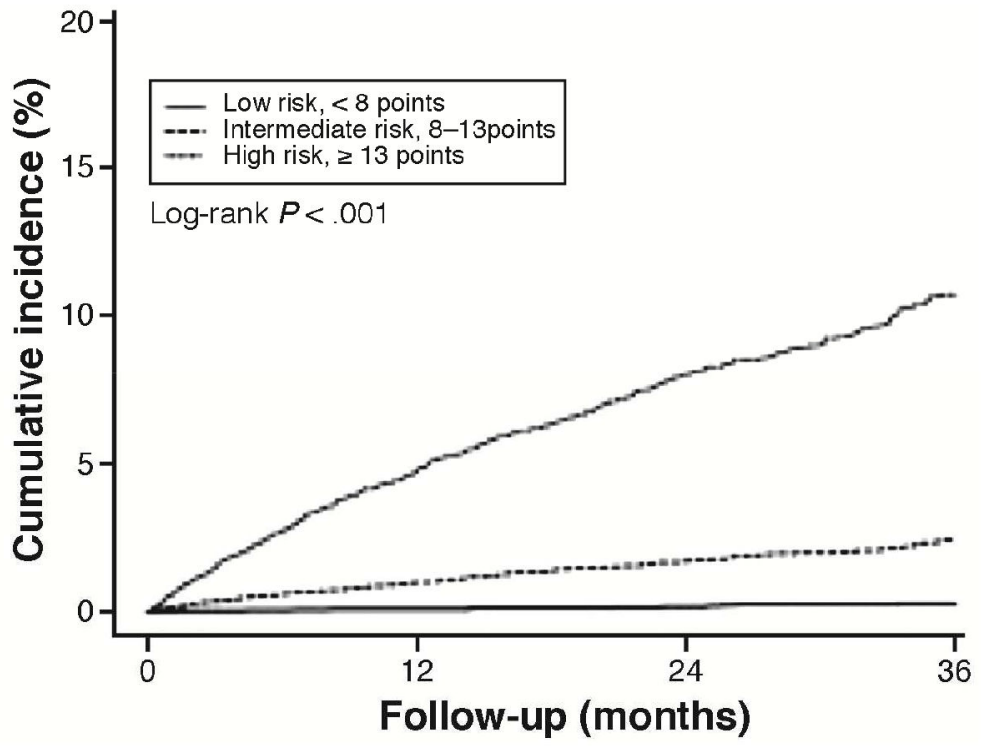

FIGURE 3.

The risk of $\mathrm{HCC}$ among patients with hepatitis B receiving continuous antiviral treatment. Adopted from ref \#34. 
Table 1.

Prognostic models for patients HCC treated with liver transplantation.

\begin{tabular}{|c|c|c|c|}
\hline Scoring System & Included Parameters \& Cutoff (points) & Recurrence Risk Stratification & 5 - yr. RFS $(\%)$ or recurrence $(\%)$ \\
\hline $\begin{array}{l}\text { MoRAL (USA) } \\
\text { N=339 } \\
\text { DDLT } 91 \% \\
\text { LDLT } 9 \%\end{array}$ & $\begin{array}{l}\text { AFP > 200: }(6) \\
\text { NLR > 5: (4) } \\
\text { Largest tumor > } 3 \mathrm{~cm}:\end{array}$ & $\begin{array}{l}0-2 \text { points: low } \\
\text { 3-6 points: medium } \\
7-10 \text { points: high } \\
>10 \text { points: very high }\end{array}$ & 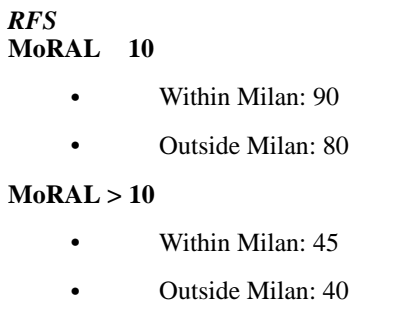 \\
\hline $\begin{array}{l}\text { MoRAL (Korea) } \\
\text { N=566 } \\
\text { LDLT } 100 \%\end{array}$ & $\begin{array}{l}\text { AFP } \\
\text { PIVKA } \\
\text { Formula= } 11 \times \text { square root PIVKA }+2 X \\
\text { square root AFP }\end{array}$ & $\begin{array}{l}\text { Low }<314.8 \\
\text { High }>314.8\end{array}$ & 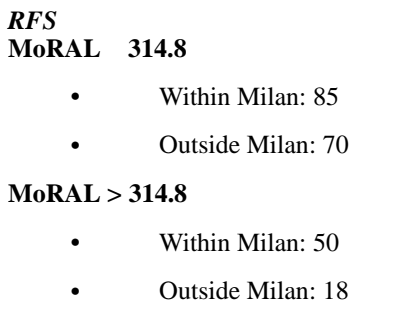 \\
\hline $\begin{array}{l}\text { TRAIN (Brussels) } \\
\text { (Time-Radiological- } \\
\text { response-Alpha- } \\
\text { fetoprotein- } \\
\text { Inflammation) } \\
\mathrm{N}=289\end{array}$ & $\begin{array}{l}\text { Radiographic response } \\
\text { AFP slope } \geq 15 \mathrm{ng} / \mathrm{ml} / \mathrm{mo} \text {. } \\
\text { NLR }>5 \\
\text { Waiting time } \leq 120 \text { days } \\
\text { Formula: } 0: 988 \text { (if } \mathrm{mRECIST}-\mathrm{PD})+0: 838 \\
\text { (if AFP slope } \geq 15: 0 \mathrm{ng} / \mathrm{mL} / \mathrm{month}+0: 452 \\
\text { (if NLR } \geq 5 \text { ) }-0: 03 \mathrm{WT} \text { ( } \mathrm{x} \text { month) }\end{array}$ & $\begin{array}{l}\text { Low risk }<1.0 \\
\text { High risk } \geq 1.0\end{array}$ & $\begin{array}{cl}\begin{array}{c}\text { Recurrence } \\
\text { TRAIN }<1\end{array} & \\
\text { - } & \text { Within Milan: } 8.4 \\
\text { - } & \text { Outside Milan: } 26 \\
\text { Train } \geq 1 & \\
\text { - } & \text { Within Milan: } 35 \\
\text { - } & \text { Outside Milan: } 100\end{array}$ \\
\hline
\end{tabular}


Table 2

\begin{tabular}{|l|l|l|}
\hline & Median OS (months) & HR (95\% CI) \\
\hline First line & & \\
\hline Lenvatinib vs. Sorafenib & 13.6 vs. 12.3 & $0.92(0.79-1.06)$ \\
\hline Second line & & \\
\hline Regorafenib vs. Placebo & 10.6 vs. 7.8 & $0.63(0.50-0.79)$ \\
\hline *Nivolumab (Sor experienced: ESC/EXP) & $15.0 / 15.6$ & NA \\
\hline Ramucirumab vs. Placebo & 8.5 vs. 7.3 & $0.710(0.531-0.949)$ \\
\hline Cabozantinib vs. Placebo & 10.2 vs. 8.0 & $0.76(0.63-0.92)$ \\
\hline
\end{tabular}

* phase I/II trial 